\title{
Description of Colombian Electricity Pricing Derivatives
}

\author{
Sellamuthu Prabakaran \\ School of Economics and Business Administration, \\ Department of Accounting \& Finance, \\ Pontificia Universidad Javeriana Cali. Cali, Colombia. \\ Email - jopraba@gmail.com
}

\begin{abstract}
s
Electricity markets are becoming a popular field of research amongst academics because of the lack of appropriate models for describing electricity price behavior and pricing derivatives instruments. Models for price dynamics must consider seasonality and spiky behavior of jumps which seem hard to model by standard jump process. Without good models for electricity price dynamics, it is difficult to think about good models for futures, forward, swaps and option pricing. In this paper we attempt to introduce an algorithm for pricing derivatives to intuition from Colombian electricity market. The main ambition of this study is fourfold: 1) First we begin our approach through to simple stochastic models. for electricity pricing. 2) Next, we derive analytical formulas for prices of electricity derivatives with different derivatives tools. 3) Then we extent short of the model for price risk in the electricity spot market 4) finally we construct the model estimation under the physical measures for Colombian electricity market. And this paper end with conclusion.
\end{abstract}

Key Words - Electricity markets, Energy Derivative, Option and Forward Contract.

\section{How to Cite:}

Prabakaran, S. (2021). Description of Colombian Electricity Pricing Derivatives. International Journal of Finance Research, 2(3). 191 - 211. DOI: https://doi.org/10.47747/ijfr.v2i3.349

\section{Introduction}

Deregulation of electricity markets has led to a considerable increase in risk accepted by market participants. The often unexpected, extreme spot price changes range even two orders of greatness and can cause severe financial problems to the efficacies that buy electricity in the wholesale market and deliver it to consumers at fixed prices. The utilities and other power market companies essential to hedge against this price risk. A forthright way to do it is to use derivatives, like forwards and options.

Here, we use the latter approach and describe the spot price dynamic models to review the electricity pricing with details of how to implement the pricing of electricity market a After specifying a model we must choose for derivatives pricing methodology. However, such approach fails in case of electricity due to extremely limited storage possibilities. 
Therefore, instead of using a discrete time model approach we employ a concept of the risk premium / market price of risk and find such pricing measure that yields the observed forward market prices. With such methodology we can originate forward prices from the spot price model and to find unambiguous formulas for premiums of European options written on spot, as well as, on forward prices.

Over the last two eras the electricity manufacturing worldwide has undergone a profound restructuring process. Particularly in Colombia, laws 142 and 143 of 1994 in addition to later reforms, opened an concentrated reorganization of the electricity market, like the creation of the wholesale electricity market (MEM) in 1995 instantaneously to the vertical unbundling of the generation, transmission, distribution, and retail activities, seeking to expand the efficiency and worth of the electricity industry. Under this new framework, the power generation and retail businesses could be competitive deregulated markets, whereas the remaining two, transmission and distribution, were recognized as regulated activities.

Colombia has a hydro-dominated electricity market. Roughly $80 \%$ of its energy comes from hydro resources, $67 \%$ of its capacity, and $50 \%$ of its firm energy-energy in an exceptionally dry period. The keystones of the wholesale electricity market in Colombia are the spot energy market and the firm energy market. The spot energy market is a single-zone hourly market that regulates the spot energy price in every hour as well as the efficient dispatch of resources.

The aim of this paper is to introduce pricing electricity derivatives to the Colombian market with an alternative formalism.

\section{Stochastic Model for Electricity Pricing Derivatives.}

In the past few years there has been a quickly cumulative literature on stochastic models for prices of electricity and other commodities. Many researchers have experimental that the models typically used in financial markets are unsuitable due to the special features of commodity prices and especially of electricity prices as described in the introduction.

In this section we will give a short estimate of some of the models considered so far in the literature and comparation them with our approach.

The special of stochastic model for electricity prices differs on the time coarseness that needs to be replicated in the model. Liquidly import/export futures and forward contracts classically have full months, quarters, or years as delivery periods, either as base load or peak load. Price estimates for single hour deliveries are in most cases only available as dayahead prices from the spot market. However, many structured Over The Market (OTC) products, such as swing options, are strongly influenced by the hourly price behavior. Since due to the non-storage stability of electricity, spot products cannot be used for hedging 
purposes, the electricity market is a highly incomplete market and pure arbitrage option pricing methods fail for most structured products.

Previous work has been focused mainly on either of the two following approaches:

- Market models for futures prices: As an alternative of modeling the spot price and deriving futures prices, the futures prices themselves are demonstrated. This method goes back to Black's model (1976), where a single futures contract is measured. Ideas from the Heath - Jarrow - Morton theory for interest rates Heath, Jarrow, and Morton (1992) are used in Clewlow and Strickland (1999), Box and Jenkins (1976), Koekebakker and Ollmar (2001) and Manoliu and Tompaidis (2002) to model the dynamics of the complete futures price curve. Such models have the benefit that the market can be considered as being complete and standard riskneutral pricing may be used. Risk-neutral parameters can often be roundabout from traded options on futures prices. The weakness of such approaches is that futures prices do not expose the information about price behavior on an hourly or even daily time scale.

- Spot price models: This model aims at apprehending the hourly price behavior by fitting their model to historical spot price data. Since there is no arbitrage kith and kin between spot prices and futures prices, in additional conventions must be made to use this model for pricing derivatives. Generally, this is done either by assuming the balanced expectation hypothesis

$$
F_{t, T}=\mathrm{E}\left[S_{T} \mid F_{t}\right]
$$

As done e.g. in Tseng and Barz (2002) to price generation assets, or by standardizing a market price of risk for each factor and then the altering to an equivalent martingale measure $P^{*}$ under which the relation $F_{t, T}=\mathrm{E}^{*}\left[S_{T} \mid F_{t}\right]$, holds.

Maximum, the models for the spot market engagement at least two risk factors: first one, seizing the short-term hourly price dynamics characterized by mean reversion and tremendously high volatility, and the other factor demonstrating long-term price behavior observed in the futures market. Since there are no liquidly traded derivatives on a daily or hourly time gauge that have a strong dependence on the short-term risk factor, it is exceptionally difficult to guesstimate the short-term market price of risk.

Through this paper we will denote $S_{t}$ the spot market price at time $t$. Since are working in a predetermined interest rate framework, we will not differentiate between forward and futures prices. Therefore, single hour futures prices at time $t$ for delivery at time $T$ are 
conditional opportunities under the equivalent martingale measure

$$
F_{t, T}=\mathrm{E}^{*}\left[S_{T} \mid F_{t}\right]
$$

Where $F_{t}=\sigma\left[S_{s}: \mathrm{s} \leq \mathrm{t}\right]$, is the natural filtration produced by the prices process.

Future prices for power delivery over a period $S_{t}=()\left[T_{1}, T_{2}\right]$ are given by

$$
F_{t, T_{1}, T_{2}}=\mathrm{E}^{*}\left[\frac{1}{T_{2}-T_{1}} \int_{T_{1}}^{T_{2}} S_{T} d T \mid F_{t}\right]=\frac{1}{T_{2}-T_{1}} \int_{T_{1}}^{T_{2}} F_{t, T} d T,
$$

Or, in a discrete time setting by

$$
F_{t, T_{1}, T_{2}}=\mathrm{E}^{*}\left[\frac{1}{T_{2}-T_{1}} \sum_{T=T_{1}}^{T_{2}-1} S_{t} \mid F_{t}\right]=\frac{1}{T_{2}-T_{1}} \sum_{T=T_{1}}^{T_{2}-1} F_{t, T} .
$$

The simplest model considering mean-reverting behavior is given by an OrnsteinUhlenbeck process. Here the price process $S_{t}$ is a diffusion process satisfying the stochastic differential equation

$$
d S_{t}=-\left(S_{t}-a\right) d t+\sigma d W_{t},
$$

Where $\left(W_{t}\right)$ is a standard Brownian motion, $\sigma$ the volatility of the development, and $\lambda$ the velocity with which the process reverts to its long term mean $a$.

In electricity markets prices show powerfully mean reverting behavior so that estimations for $\lambda$ are quite large. Representative characteristic times for mean reversion are within a few days. Therefore, this model has the main disadvantage that futures prices are nearly constant over time, since under the assumption of Koekebakker and Ollmar (2001) the futures price is given by

$$
F_{t, T}=\mathrm{a}\left(1-e^{0-\lambda(T-t)}\right)+S_{t} e^{-\lambda(T-t)}
$$

For this motive, several authors proposed a two-factor model, see e.g. Gibson and Schwartz (1990), Pilipovic (1988) and Schwartz and Smith (2000). In Pilipovic (1988) a model of the form

$$
d S_{t}=-\lambda\left(S_{t}-Y_{t}\right) d t+\sigma d W_{t}
$$


is suggested, where $Y_{t}$ is a Brownian motion. A parallel model is given in Schwartz and Smith (2000), where commodity prices are designated in the form

$$
S_{t}=\exp \left(X_{t}+Y_{t}\right),
$$

where $\left(X_{t}\right)$ is an Ornstein - Uhlenbeck process accountable for the short-term variation and $\left(Y_{t}\right)$ is a Brownian motion recitation the long-term dynamics. From this model, we will present in and can be considered as an extension of the ideas of Schwartz and Smith (2000). All models are measured so far did not contemplate seasonality. Some authors purely abandonment this serious difficulty. Others propose to use deterministic seasonality designated by sinusoidal functions, see Barlow (2002), Elliott, Sick, and Stein (2003), Geman, and Roncoroni (2003), and Schwartz and Smith (2000). In Knittel and Roberts (2001) it is suggested to use equation (5) with a long run mean $a_{t}$ describing the seasonal patterns. A general deterministic seasonality is proposed in Knittel and Roberts (2001) and Gibson and Schwartz (1990). Here, the spot price is modeled as

$$
S_{t}=f(\mathrm{t})+X_{t} \text { or } S_{t}=\exp \left(f(\mathrm{t})+X_{t}\right)
$$

with an arbitrary deterministic function $f(t)$ and a mean-reverting stochastic process $X_{t}$

In our approach, the deterministic component $f(t)$ is specified by the load forecast 't and additional stochastic behavior is introduced using SARIMA models for the time series of load and prices.

Many authors are attempted different way to account for price spikes. One possibility to manage with spikes is the overview of jump terms, see Box and Jenkins (1976), Knittel and Roberts (2001) and Heath, Jarrow, and Morton (1992). The main disparagement for these models is that under the typical assumption of a jump-diffusion model a huge upward jump is not necessarily tailed by a great downward jump. Therefore, some authors suggest hidden Markov models, known as Markovian regime-switching models, where it is defined that upward jumps are tracked by downward jumps. Such models have been reflected e. g. in De Jong, and Huisman (2002), Deng (2000), Elliott, Sick, and Stein (2003), Huisman, and Mahieu (2001) and Kholodnyi (2000). Regime-switching models are very instinctive candidates for electricity price models since there are some clear physical reasons for switches of regimes such as forced outages of significant power plants. On the other hand, it gives the impression to be problematic to combine regime-switching with seasonality. 
In Additional, another approach is interested by the economic background for price spikes. Prices are originated mainly by supply and demand (load). Therefore, the non-linear relation between load and price should be considered in the model. This non-linear renovation is called the 'power stack function' in Eydeland, and Geman (1999) and Skantze, Gubina, and Ilic, (2000). They recommend an exponential function for that determination. A similar model for spot prices has recently been measured in Black (1976), where the relation

$$
S_{t}=f\left(X_{t}\right)
$$

is suggested with $X_{t}$ being an Ornstein- Uhlenbeck process, and $f$ a power function. We also choose an method based on the power stack function, since there is a natural understanding of this non-linear transform in terms of the merit order curve.

\section{Electricity Derivatives Pricing}

\section{Electricity options}

The power industry had been exploiting the idea of options through surrounded terms and conditions in many supplies and obtaining contracts for decades, deprived of obviously recognizing and valuing the options until the commencement of the electricity industry rearrangement in the U.K., the U.S., and the Nordic countries in the 1990s. The development of the electricity wholesale markets, and the dissemination of option pricing and risk management techniques have shaped electricity options not only based on the underlying price attribute (with plain vanilla electricity call and put options), but also other attributes like volume, delivery location and timing, quality, and fuel type.

Fundamentally, a counterparty of each financial option can be shaped in the domain of electricity options and by substituting the underlying in a financial option with electricity market Hull (2000) for introduction to various kinds of financial options (American Style, European Style, Exchange Traded Options, Over the Counter Options, Option Type by Underlying Security and Option Type by Expiration). At this point, we entitle a sample of electricity options that are frequently utilized in risk management applications in generation and distribution sectors. These options are generally had short- to medium maturity times such as months or a couple of years. Options with maturity times longer than three years are usually entrenched in long-term supply or purchase contracts, which are termed as organized transactions. 
Now, we turn to pricing of a European call option written on the electricity spot price. Recall, that the European option is a contract that gives the buyer the right to buy/sell the underlying commodity at some future date $t$ (called maturity) at a certain price $K$ (called the strike price). First, we find the pricing measure $Q^{\lambda}$. Like Merton (1976) in the context of jump-diffusion processes we assume that the dynamics of spikes and drops are the same in the actual and pricing measures. We start with finding the spot price dynamics under $\lambda$ parameterization.

Let $\lambda(u)$ be a deterministic function square-integrable on $u \in\left[0, T_{\max }\right]$, where $T_{\max }$ is a time horizon long enough to contain all maturities of derivatives quoted in the market, and introduce a new process $W_{t}^{\lambda}$ :

$$
W_{t}^{\lambda}=W_{t}+\int_{0}^{t} \frac{\lambda(u)}{\sigma_{b}} d u,
$$

where $\sigma_{b}$ is the volatility of the base regime. From the Girsanov theorem we have that $W_{t}^{\lambda}$ is a Wiener process under a new measure $Q^{\lambda}$ defined as

$$
\frac{d Q^{\lambda}}{d Q}=\exp \left[-\int_{0}^{T_{\max }} \frac{\lambda(u)}{\sigma_{b}} d W_{u}-\frac{1}{2} \int_{o}^{T_{\max }}\left(\frac{\lambda(u)}{\sigma_{b}}\right)^{2} d u\right]
$$

with the filtration $F_{t}^{W}$, being the natural filtration of the process $W_{t}$.

Now, the base regime process $X_{t, b}$ can be rewritten as:

$$
d X_{t, b}=\left[\alpha-\lambda(t)-\beta X_{t, b}\right] d t+\sigma_{b} d W_{t}^{\lambda}
$$

and the expected future spot price is given by:

$$
\begin{gathered}
E^{\lambda}\left(P_{t} \mid F_{0}\right)=p_{b b}^{(t)}\left[X_{0} e^{-\beta t}+\frac{\alpha}{\beta}\left(1-e^{-\beta t}\right)-\int_{0}^{t} e^{-\beta(t-u)} \lambda(u) d u\right]+p_{b s}^{(t)}\left(e^{\mu_{s}+\frac{1}{2} \sigma_{s}^{2}}+c_{s}\right)+ \\
p_{b d}^{(t)}\left(-e^{\mu_{d}+\frac{1}{2} \sigma_{d}^{2}}+c_{d}\right)+g_{t}
\end{gathered}
$$

The function $\lambda(t)$ can be calibrated to the market forward prices so that $E^{\lambda}\left(P_{t} \mid F_{0}\right)=f_{0}^{t}$, e.g. by using some fitting procedure (like the least squares minimization). Alternatively, one can find the risk premium and then use the relation between the market price of risk $\lambda(t)$ and the risk premium:

$$
p_{b b}^{(t)} \int_{0}^{t} e^{-\beta(t-u)} \lambda(u) d u=R P(t)
$$


which is a simple consequence of the fact that $R P(t)=E\left(P_{t} \mid F_{0}\right)-E^{\lambda}\left(P_{t} \mid F_{o}\right)$, formula (15) and Ito's lemma.

Now, the price of a European call option written on the electricity spot price can be derived.

Option price formula. If the electricity spot price $P_{t}$ is given by the MRS model then the price of a European call option written on $P_{t}$ with strike price $K$ and maturity $T$ is equal to:

$$
C_{T}(K)=e^{-r T}\left\lfloor p_{b b}^{(T)} C_{T, b}(K)+p_{b s}^{(T)} C_{T, s}(K)+p_{b d}^{(T)} C_{T, d}(K)\right\rfloor,
$$

where

$$
\begin{gathered}
C_{T, b}(K)=\frac{s}{\sqrt{2 \pi}} \exp \left(-\frac{\left(K^{\prime}-m\right)^{2}}{2 s^{2}}\right)+\left(m-K^{\prime}\right)\left[1-\Phi\left(\frac{K^{\prime}-m}{s}\right)\right], \\
C_{T, s}(K)=\mathrm{II}_{\left\{K^{\prime}>\mathrm{C}_{s}\right\}}\left\{\exp \left(\mu_{s}+\frac{\sigma_{s}^{2}}{2}\right)\left[1-\Phi\left(\frac{\log \left(K^{\prime}-c_{s}\right)-\mu_{s}-\sigma_{s}^{2}}{\sigma_{s}}\right)\right]-\left(K^{\prime}-C_{s}\right)\left[1-F_{L N\left(\mu_{s}, \sigma_{s}^{2}\right)}\left(K^{\prime}-c_{s}\right)\right]\right\} \\
+\mathrm{II}_{\left\{K^{\prime} \leq c_{s}\right\}}\left[\exp \left(\mu_{s}+\frac{\sigma_{s}^{2}}{2}\right)+c_{s}-K^{\prime}\right]
\end{gathered}
$$

and

$C_{T, d}(K)=\Pi_{\left\{k^{\prime}<c_{d}\right\}}\left\{-\exp \left(\mu_{d}+\frac{\sigma_{d}^{2}}{2}\right) \Phi\left[\frac{\log \left(c_{d}-K^{\prime}\right)-\mu_{d}-\sigma_{d}^{2}}{\sigma_{d}}\right]+\left(c_{d}-K^{\prime}\right) F_{L N\left(\mu_{d}, \sigma_{d}^{2}\right)}\left(c_{d}-K^{\prime}\right)\right\}$

Further, $\quad K^{\prime}=K-g_{T}, m=X_{0} e^{-\beta T}+\frac{\alpha}{\beta}\left(1-e^{-\beta T}\right)-\int_{0}^{T} e^{-\beta(T-u)} \lambda(u) d u, s^{2}=\frac{\sigma_{b}^{2}}{2 \beta}\left(1-e^{-2 \beta T}\right) \quad$ and $F_{L N\left(\mu, \sigma^{2}\right)}$ is the cumulative distribution function of the log-normal distribution with parameters $\mu$ and $\sigma^{2}$.

Here, we assume that the option is settled in an infinitesimal period $[T, T+\Delta]$. However, in practice, the electricity spot price usually corresponds to a delivery during some period (e.g. an hour, a day) and, hence, the maturity of the option should be specified on the same timescale. On the other hand, the examined spot price quotations usually represent some delivery period. For example, if the measured data is quoted daily, then the maturity of the option would be also given in daily timescale and would correspond to daily delivery.

\section{$\underline{\text { Electricity Forwards }}$}


An Electricity forward contract is a customized contract between two parties to buy or sell an asset at a specified price on a future date. A forward contract can be used for hedging or speculation, although its non-standardized nature makes it particularly apt for hedging. Electricity forward contracts characterize the obligation to buy or sell a fixed amount of electricity at a pre-specified agreed price, known as the forward price, at specific time in the future (called maturity or expiration time). In other words, electricity forwards are convention tailored supply contracts between a buyer and a seller, where the buyer is obligated to take power and the seller is obligated to supply. The payoff of a forward contract auspicious to deliver one unit of electricity at price $\mathrm{F}$ at a future time $T$ is:

Payoff of a Forward Contract $=\left(S_{T}-F\right)$

Where $S_{T}$ is the electricity spot price at time $T$. Although the payoff function (1) appears to be the same as for any financial forwards, electricity forwards differ from other financial and commodity forward contracts in that the underlying electricity is a different commodity at different times. The settlement price $S_{T}$ is usually calculated based on the average price of electricity over the delivery period at the maturity time $T$.

Undoubtedly, the most popular electricity derivatives are the forward contracts. Recall that a forward contract is an agreement to buy (sell) a with specific amount of the underlying (here MWh of electricity) at a specified forward date. Settlement of the contract can be specified with physical delivery of electricity or with only financial clearing. Both types of settlement are in the following called delivery date. Denote the price at time $t$ of a forward contract with a delivery at time $T$ by $f_{t}^{T}$. There is no investment at the of entering a forward contract, the expected future payoff under the pricing measure should fulfill:

$$
E^{\lambda}\left(P_{T}-f_{t}^{T} \mid F_{t}\right)=0
$$

what implies that

$$
f_{t}^{T}=E^{\lambda}\left(P_{T} \mid F_{t}\right)
$$

Observe, that now we define the price of a forward contract at any future date $t$. This is motivation by the circumstance that the valuation at time 0 of an option written on a forward contract requires the knowledge about the forward price dynamics at the option's maturity $t$ 
Forward price formula. If the electricity spot price $P_{t}$ is given by the MRS model, then the price at time $t$ of a forward contract written on $P_{t}$ with a delivery at time $T$ is given by the following formula

$$
\begin{aligned}
& f_{t}^{T}=P\left(R_{[T]}=b \mid F_{t}\right)\left[E^{\lambda}\left(X_{t, b} \mid F_{t}\right) e^{-\beta(T-t)}+\frac{\alpha}{\beta}\left(1-e^{-\beta(T-t)}\right)-\int_{t}^{T} e^{-\beta(T-u)} \lambda(u) d u\right]+ \\
& P\left(R_{[T]}=s \mid F_{t}\right)\left(e^{\mu_{s}+\frac{1}{2} \sigma_{s}^{2}}+c_{s}\right)+P\left(R_{[T]}=d \mid F_{t}\right)\left(c_{d}-e^{\mu_{d}+\frac{1}{2} \sigma_{d}^{2}}\right)+g t
\end{aligned}
$$

where $P\left(R_{[T]}=i \mid F_{t}\right)=\sum_{j \in\{b, s, d\}} P\left(R_{[T]}=i \mid R_{[t]}=j\right) \Pi_{\left\{R_{[t]}=j\right\}}$.

Note that in the above formula $E^{\lambda}\left(X_{t, b} \mid F_{t}\right)$ is used, since this expectation depends on the state process value at time $t$. Namely, if $R_{t}=b$ then $E^{\lambda}\left(X_{t, b} \mid F_{t}\right)=X_{t, b}=X_{t}$. On the other hand, if at time $t$ a spike or a drop occurred then $E^{\lambda}\left(X_{t, b} \mid F_{t}\right)=E^{\lambda}\left(X_{t, b} \mid F_{t-1}\right)$ and again this expectation is dependent on $R_{t-1}$ value.

When deriving the forward price dynamics, we must remember that the belongings of the obtained model should observe with the observed market prices. One of the most pronounced features of the market forward prices is the detected term structure of volatility, called the Samuelson effect. Exactly, the volatility of the forward prices is moderately law for distant delivery periods, however, it increases quickly with impending maturity of the contracts.

Here, the forward price volatility is described by the part $P\left(R_{[T]}=b \mid F_{t}\right) E^{\lambda}\left(X_{t, b} \mid F_{t}\right) e^{-\beta(T-t)}$ of formula (22). Hence, it is specified by the volatility of the spot price base regime scaled with $e^{-\beta(T-t)}$ and the corresponding probability of switching to the base regime. Observe that the scaling factor $e^{-\beta(T-t)}$ exhibits the Samuelson effect as it increases to 1 with $t$ approaching maturity time $T$. Moreover, the forward price volatility, again due to the scaling factor, is lower than the spot price volatility. This is following the behavior of the market spot and forward prices.

Electricity forward contracts listed on energy exchanges are usually settled during a certain period (a week, a month, a year, etc.). Denote the price at time $t$ of a forward contract 
settled during the period $\left[T_{1}, T_{2}\right]$ by $f_{t}^{\left[T_{1}, T_{2}\right]}$. Obviously, the latter is the mean price of forward contracts with delivery during the period $\left[T_{1}, T_{2}\right]$, namely:

$$
f_{t}^{\left[T_{1}, T_{2}\right]}=\int_{T_{1}}^{T_{2}} w\left(T_{1}, T_{2}, T\right) f_{t}^{T} d T=\int_{T_{1}}^{T_{2}} w\left(T_{1}, T_{2}, T\right) E^{\lambda}\left(P_{T} \mid F_{t}\right) d T,
$$

where $w\left(T_{1}, T_{2}, T\right)$ is the weight function representing the time value of money. The form of $w$ depends on the contract specification. For contracts settled at maturity we have $w\left(T_{1}, T_{2}, T\right)=\frac{1}{T_{1}-T_{2}}$, while for instant settlement $w\left(T_{1}, T_{2}, T\right)=\frac{r e^{-r T}}{e^{-r T_{1}}-e^{-r T_{2}}}$, where $r>0$ is the interest rate (Benth et al., 2008a). The price $f_{t}^{\left[T_{1}, T_{2}\right]}$ can be obtained from formulas (3.10) and (3.11). Indeed, we have:

$$
\begin{aligned}
& f_{t}^{\left[T_{1}, T_{2}\right]}=E^{\lambda}\left(X_{t, b} \mid F_{t}\right) \int_{T_{l}}^{T_{2}} w\left(T_{1}, T_{2}, T\right) P\left(R_{[T]}=b \mid F_{t}\right) e^{-\beta(T-t)} d t+ \\
& \int_{T_{l}}^{T_{2}} w\left(T_{1}, T_{2}, T\right) P\left(R_{[T]}=b \mid F_{t}\right)\left[\frac{\alpha}{\beta}\left(1-e^{-\beta(T-t)}\right)-\int_{t}^{T} e^{-\beta(T-u)} \lambda(u) d u\right] d T+ \\
& \left(e^{\mu_{s}+\frac{1}{2} \sigma_{s}^{2}}+c_{s}\right) \int_{T_{l}}^{T_{2}} w\left(T_{1}, T_{2}, T\right) P\left(R_{[T]}=s \mid F_{t}\right) d T+ \\
& \left(c_{d}-e^{\mu_{d}+\frac{1}{2} \sigma_{d}^{2}}\right) \int_{T_{l}}^{T_{2}} w\left(T_{1}, T_{2}, T\right) P\left(R_{[T]}=d \mid F_{t}\right) d T+\int_{T_{l}}^{T_{2}} w\left(T_{l}, T_{2}, T\right) g_{T} d T
\end{aligned}
$$

\section{OPTIONS WRITTEN ON ELECTRICITY FORWARD CONTRACTS}

Lastly, we derive an unambiguous formula for a European call option written on a forward contract delivering electricity during a specified period. Observe, that the forward price $f_{t}^{\left[T_{1}, T_{2}\right]}$ depends on the spot price at time $t$ and, consequently, also on the state process value at time $t$.

Now, we will consider an option written on an electricity forward contract with settlement during a specified period, as it is the most popular specification of electricity options on energy exchanges. For example, in the European Energy Exchange (EEX) market there are options written on forward contracts with monthly, quarterly, and yearly settlement periods. The maturity of such options is set to the quarter business day before the beginning of the underlying contract's settlement period. 
Price formula for an option written on a forward contract. The price of a European call option with strike price $K$ and maturity $t$ written on a forward contract with delivery during the period $\left[T_{1}, T_{2}\right]$ is equal to:

$$
\begin{aligned}
& C f_{t}^{\left[T_{1}, T_{2}\right]}(K)=e^{-r t}\left\{A_{0}(b) C_{t, b}\left(\frac{K-B_{0}(b)}{A_{0}(b)}+g_{t}\right) P\left(R_{[t]}=b \mid R_{0}=b\right)+\right. \\
& \left.\sum_{i \hat{I}\{s, d\}} \sum_{k=1}^{[t]}\left[A_{k}(i) C_{[t]-k+1, b}\left(\frac{K-B_{k}(i)}{A_{k}(i)}+g_{[t]-k+1}\right) \times P\left(R_{[t]}=i, R_{[t]-1}^{1} b, \ldots, R_{[t]-k}=b \mid R_{0}=b\right)\right]\right\}
\end{aligned}
$$

Where

$$
\begin{aligned}
A_{k}(i)= & \int_{T_{1}}^{T_{2}} w\left(T_{1}, T_{2}, T\right) P\left(R_{[T]}=b \mid R_{[t]}=i\right) e^{-\beta(T-[t]+k-1)} d T \\
& A_{0}(b)=\int_{T_{1}}^{T_{2}} w\left(T_{1}, T_{2}, T\right) P\left(R_{[T]}=b \mid R_{[t]}=b\right) e^{-\beta(T-t)} d T
\end{aligned}
$$

$B_{k}(i)=\int_{T_{l}}^{T_{2}} w\left(T_{1}, T_{2}, T\right) P\left(R_{[T]}=b \mid R_{[t]}=i\right) \times\left[\frac{\alpha}{\beta}\left(1-e^{-\beta(T-[t]+k-l)}\right)-\int_{[t]-k+1}^{T} e^{-\beta(T-u)} \lambda(u) d u\right] d T+$

$$
\begin{aligned}
& \left(e^{\mu_{s}+\frac{1}{2} \sigma_{s}^{2}}+c_{s}\right) \int_{T_{l}}^{T_{2}} w\left(T_{1}, T_{2}, T\right) P\left(R_{[T]}=s \mid R_{[t]}=i\right) d T+ \\
& \left(c_{d}-e^{\mu_{d}+\frac{1}{2} \sigma_{d}^{2}}\right) \int_{T_{l}}^{T_{2}} w\left(T_{l}, T_{2}, T\right) P\left(R_{[T]}=s \mid R_{[t]}=i\right) d T+\int_{T_{I}}^{T_{2}} w\left(T_{l}, T_{2}, T\right) g_{T} d T
\end{aligned}
$$

$$
\begin{aligned}
& B_{0}(b)=\int_{T_{l}}^{T_{2}} w\left(T_{1}, T_{2}, T\right) P\left(R_{[T]}=b \mid R_{[t]}=b\right)\left[\frac{\alpha}{\beta}\left(1-e^{-\beta(T-t)}\right)-\int_{t}^{T} \frac{\alpha}{\beta}\left(e^{-\beta(T-u)} \lambda(u) d u\right)\right] d T+ \\
& \left(e^{\mu_{s}+\frac{l}{2} \sigma_{s}^{2}}+c_{s}\right) \int_{T_{l}}^{T_{2}} w\left(T_{l}, T_{2}, T\right) P\left(R_{[T]}=s \mid R_{[t]}=b\right) d T+ \\
& \left(c_{d}-e^{\mu_{d}+\frac{1}{2} \sigma_{d}^{2}}\right) \int_{T_{l}}^{T_{2}} w\left(T_{l}, T_{2}, T\right) P\left(R_{[T]}=d \mid R_{[t]}=b\right) d T+\int_{T_{l}}^{T_{2}} w\left(T_{l}, T_{2}, T\right) g_{T} d T
\end{aligned}
$$

And $C_{t, b}(K)$ is the "base regime part" of the price of a European call option written on the electricity spot price with maturity $t$ and strike $K$, see equation (3.7) with $T=t$.

\section{MODEL FOR PRICE RISK}

Electricity have proven to be the most volatile commodity, and it is not the exception in the 
Colombian competitive electricity market. It makes it compulsory to develop an appropriate risk management to maximize agents' benefits and minimize the corresponding uncertainty upon them. Among the risks that firms must handle with, are macroeconomic risk, price risk, market risk, credit risk, regulatory risk, country risk, and quantity risk. The last one is a non- tradable risk, and an implicit feature of electricity, which has to do with the amount of energy that will be demanded in the future, which follows a stochastic process as well as the spot price. This situation directly impacts the firm's revenues and makes it necessary to include it when designing the hedging portfolio.

Here, we developed a financial theory for research studies to find how to address this problem. In Liu, and $\mathrm{Wu}$ (2007) electricity risk management is handled by a multi-market trading approach, while other references like Huisman, Mahieu, and Schlichter (nd) get emphasis on best risk management trough forward on-peak and off-peak contracts. Nevertheless, the electricity derivatives are progressively studied and used around the world to manage the financial risks and resource appropriateness of power markets, like it is advocated in Chao, and Wilson (nd). Particularly Villareal, and Soto (nd) proposed a financial call option to hedge against critic hydrologic scenarios in the Colombian electricity system by ensuring generation adequacy.

Further, derivative instruments have been developed to also handle the quantity risk, like swing options, weather derivatives, interruptible contracts, among other instruments named in Deng, and Oren(2006). The features of these derivative products make them be usually traded over the counter (OTC); therefore, they are low liquidity instruments, which is why they are not regarded in this paper. However, references Oum, Oren, and Deng (2006) and Prokopczuk, Rachev, Schindlmayr, and Truck,(nd) study quantity risk.

Oum, Y., Oren, S. (nd) deal with the static hedging problem of a LSE who has to serve an uncertain electricity demand $q$ at a regulated fixed price $r$ in a single period from 0 to 1 . Besides, the LSE procures the electricity to serve his customers, from the wholesale market at a spot price $p$. Hence the profit of the LSE would be:

$$
y(p, q)=(r-p) \cdot q
$$

To protect himself against price risk, the LSE can take a long position in $q^{-9}$ forward contracts at a fixed forward price $F$. However, the LSE will face another risk that arises 
from the fact that demand $\bar{q}$ may vary from the expected value at time 0 to the actually realized value at time 1 . Then, if the actual demand realized by the retailer agent is $\bar{q}+\Delta q$, then, the share of the profit in Chao and Wilson (nd), that is at risk is: $(r-p) \cdot \Delta q$, where $\Delta q$ could be different to zero (gains/losses).

To deal with this hedging problem, the authors derive the optimal hedging portfolio as a function of spot price $p$. That is:

$$
Y(p, q)=(r-p) q+x(p)
$$

where $x(p)$ is the optimal hedging portfolio as function of the spot price $p$.

Regarding the LSE's preferences and risk aversion profile, it is necessary to identify its utility function $U$ over total profit $Y$. In turn, because of the positive correlation between price and demand, which will be evident later in the paper for the Colombian electricity market, there exists a joint probability function $f(p, q)$ defined on the probability measure $P$, which characterizes the behavior of $p$ and $q$ at time 1 . On the other side, $Q$ is a riskneutral probability measure by which the hedging instruments are priced and $g(p)$ is the probability density function of $p$ under $Q$. Keeping this in mind, in the optimization problem is formulated as follows:

$$
\begin{aligned}
& x(p) E[U(Y(p, q))] \\
& \text { s.t. } E^{Q}[x(p)]=0
\end{aligned}
$$

where $E[\cdot]$ and $E^{Q}[\cdot]$ denote expectations under probability measures $P$ and $Q$, respectively. In (30) the constraint implies that the hedge portfolio $x(p)$ is self-financing, that is, the LSE can borrow funds in the money market, in order to purchase the derivative instruments needed to obtain the maximum expected utility over the total profit $Y(p, q)$. This constraint also means that there are not arbitrage opportunities through this hedging portfolio, under a constant risk-free rate. The optimization process yields as a result the optimal payoff function $x^{*}(p)$.

Through an extension of the fundamental calculus theorem, it is demonstrated that any twice continuously differentiable function can be written as follows, for fixed value $F$ :

$$
x(p)=x(F) \cdot 1+x^{\prime}(F) \cdot(p-F)+\int_{0}^{F} x^{\prime \prime}(K) \cdot(K-p)^{+} d K+\int_{F}^{\infty} x^{\prime \prime}(K) \cdot(p-K)^{+} d K
$$


The expression $(\cdot)^{+}$in the above equation, is equivalent to the function $\max (\cdot, 0)$. It is important to note that in the expressions above $1,(p-f), \max (K-p, 0), \max (p-K, 0)$ correspond to the payoff profile of a bond, forward contract, put option and call option, respectively. In this sense, and remaining the LEGO@ approach theory presented, with $x(F)$ units in bonds, $x^{\prime}(F)$ units of forward contracts, $x^{\prime \prime}(K) d K$ units of put options with strike price $K(K<F)$ and $x^{\prime \prime}(K) d K$ units of call options with strike price $K^{\prime}\left(K^{\prime}>F\right)$, it is possible to replicate the resultant optimal hedging portfolio $x^{*}(p)$ from the optimization process. This financial derivative have as underlying asset the electricity spot price.

Viewed from this angle, to replicate the optimal function $x^{*}(p)$, the equation (32) implies that it is necessary to have a set of continuum strike prices for both put and call options. Since markets are incomplete, there are no markets with that amount of strike prices on board, and assuming that there is only $n$ put options and $m$ call options available in the market, Oum, Deng and Orend proposed a portfolio compounded by $x(F)$ units of bonds, $x^{\prime}(F)$ units of forward contracts, $\frac{1}{2}\left(x^{\prime}\left(K_{i+1}\right)-x^{\prime}\left(K_{i-1}\right)\right)$ units of put options with strike prices $K_{i}, i=1, \ldots, n$. and $\frac{1}{2}\left(x^{\prime}\left(K_{j+1}\right)-x^{\prime}\left(K_{j-1}\right)\right)$ units of call options with strike prices $K_{j}, i=1, \ldots, m$.

The errors of this replicating strategy are calculated depending on the range in which spot price is realized at time 1 .

\section{MODEL ESTIMATION UNDER THE PHYSICAL MEASURE}

The non-storability feature of electricity along with the steeply rising supply and the inelastic demand curve, both schematically represented in Figure 1, makes the electricity price $p$ and the electricity demand $q$ to be positive correlated. It happens in this way in the Colombian electricity market, since the dispatch is carried out in order of merit, so, when demand rises during on-peak hours, it forces the system to put in operation a more expensive generation resource, increasing the spot price as well.

Additional to the fact explained above, throughout summer seasons, the hydropower plants which are technologies with lower variable costs, reduce their power production due to natural water inflows shortages and of course to a diminishment in water reserves into reservoirs. This turns out in a higher marginal system cost, so an increment in demand translates into an increase in the spot price. This increment in the spot price reaches larger values during summer seasons than during winter seasons. Therefore, the correlation 
Vol 2, No.3, September 2021

between $p$ and $q$ is bigger during dry periods in the Colombian wholesale electricity market.

The earlier reasons justify the usage of the price-quantity hedging strategy presented, to design suitable derivative instruments to be used by the agents of the electricity market.

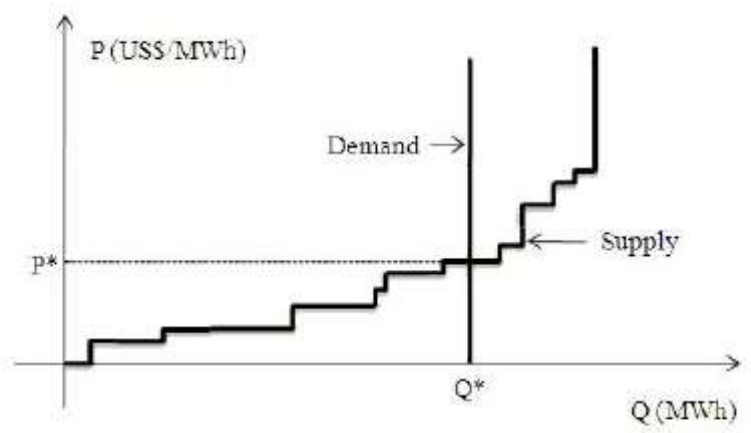

Figure 1: Supply and demand equilibria at Colombian electricity market.

The advantage offered by the financial derivative products, arises from the fact that is likely to achieve the maximum expected value of total profit $Y(p, q)$, together with the minimum deviation of this profit (which means less uncertainty over LSE's total profit), after building a hedging portfolio with those instruments. To do so, a utility function to represent the risk aversion preferences of the agents like a mean-variance utility function is a good candidate to accomplish both goals at the same time. Here it is utilized the same mean-variance utility function which has been used in financial hedging literature to deal with non-tradable risk:

$$
U(Y)=Y-\frac{1}{2} a\left(Y^{2}-E[Y]^{2}\right)
$$

where $a$ represents the agent's risk aversion coefficient. Certainly, maximizing the expected value of the utility function in (33) $\left(E[U(Y)]=E[Y]-\frac{1}{2} \operatorname{aVar}(Y)\right)$, is equivalent to maximize the expected value of $Y(p, q)$ and to minimize the variance of (29), that is the advantage provided by a price-quantity hedging portfolio.

In equation (33) it is presented the optimal hedging function constrained to the meanvariance utility function. The arithmetic procedure to find this expression is clearly developed. 


$$
x^{*}(p)=\frac{1}{a}\left(1-\frac{g(p) / f_{p}(p)}{E^{Q}\left[g(p) / f_{p}(p)\right]}\right)-E[y(p, q) \mid p]+E^{Q}\left[E \left[y(p, q) p \rrbracket \frac{g(p) / f_{p}(p)}{E^{Q}\left[g(p) / f_{p}(p)\right]}\right.\right.
$$

where $f_{p}(p)$ is the marginal density function of $p$ under the probability measure $P$.

From the perspective of a clearing house or a market maker, who is willing to design the most adequate hedging instruments for all the participants in the market, the goodness of this model, is that equation (34) can be used to calculate the optimal payoff function for each retailer, which will determine the optimal hedging instruments needed by each retailer. Once this task is undertaken, and seeking to find the optimal hedging instruments for all of them jointly interacting in the market, here it is proposed to estimate a weighted average market payoff function $\bar{x}(p)$ as presented in equation (35), which will represent the joint needs of all the agents and could be used to determine general hedging instruments suitable for all-, by no favoring big or small agents and giving to each of them the same hedging opportunities.

$$
\begin{gathered}
\bar{x}(p)=\sum_{i=1}^{N} w_{i} x_{i}^{*}(p) \\
w_{i}=\frac{\int_{0}^{S} x_{i}^{*}(p) d p}{\sum_{i=1}^{N} \int_{0}^{S} x_{i}^{*}(p) d p}
\end{gathered}
$$

The variable $S$ corresponds to a price-cap value defined under the market maker or clearing house criteria. Within the Colombian framework, this variable could be interpreted as the scarcity price associated to the firm energy market described above, since hedging above this price already exists given the call options related to that market.

After calculating $\bar{x}(p)$, the replicating methodology suggested is used to find the right number of bonds, forward contracts, put, and call options needed to best describe the behavior of $\bar{x}(p)$.

Some of these financial instruments are currently available in the Colombian market, except the financial options. The simplest of them, bonds, can be found available in the stock market; forward contracts needed to replicate the function $x^{*}(p)$, could be either the current bilateral contracts (not suggested), the forward contracts that are planned to be included in MOR proposal, or even better, future contracts which are quite possibly to be launched the next year by a central chamber of counter-party risk (CRCC) to be established 
Vol 2, No.3, September 2021

soon in Colombia. Since there are no financial options to replicate the optimal hedging function on the current electricity market.

Now, for the empirical analysis and the estimation procedure we use data from the Colombian electricity markets daily market representative rate value (in Colombian Pesos) the period from January 1, 1995, to December 22013 with 6853 observations.

The fig 2 time series of the resulting price for the above Colombian electricity daily price.

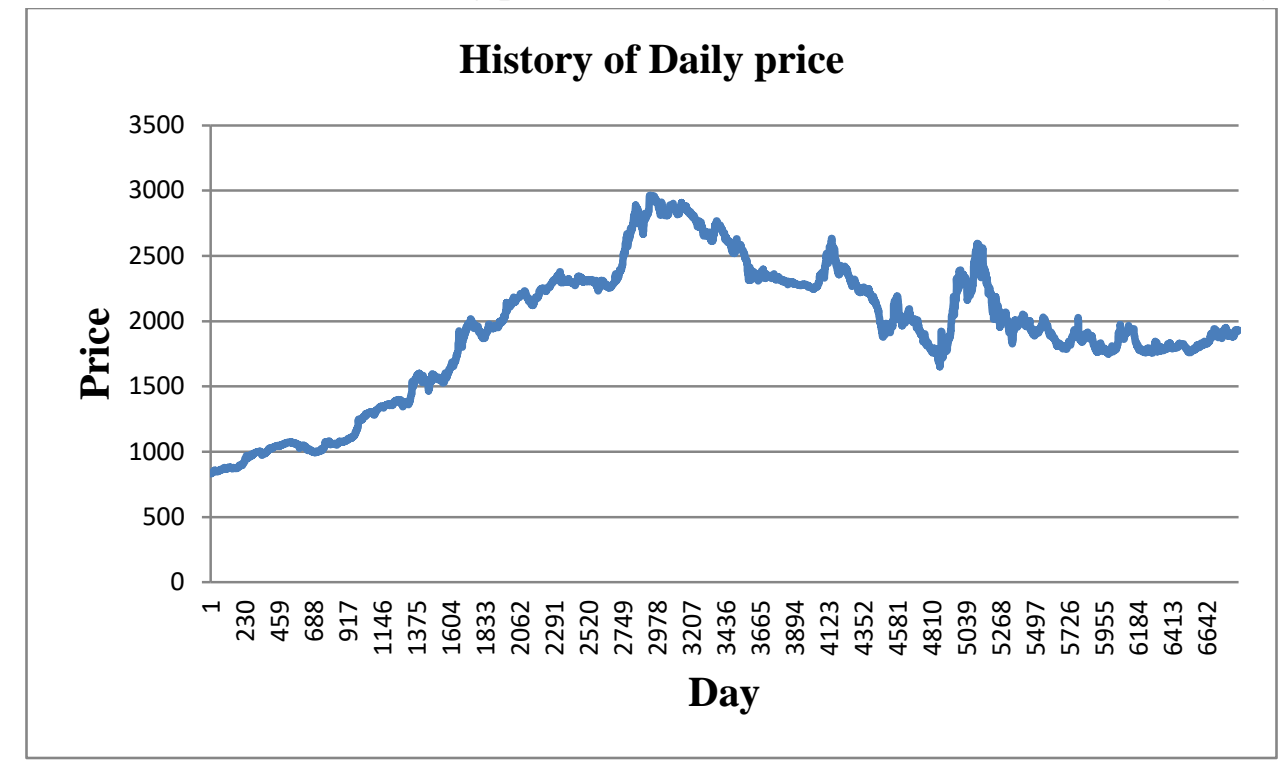

Fig 2: History of Daily price

The fig 3 gives the QQ plot for electricity daily price.

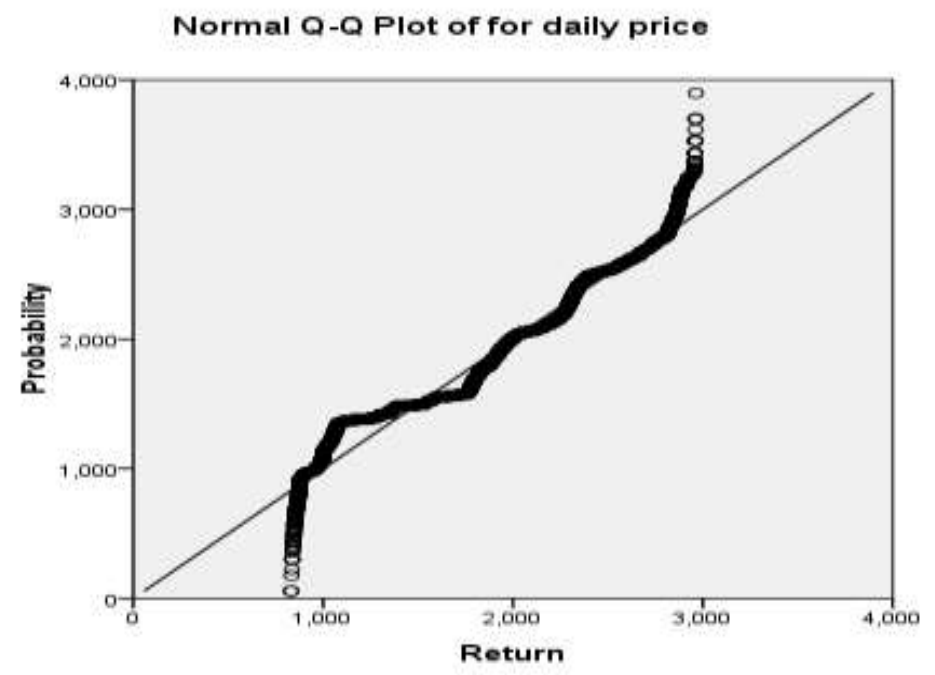


Fig 3: Normal QQ plot.

\section{Conclusion}

From the above discussion, in this paper we attempted to introduce an algorithm for pricing derivatives to intuition from Colombian electricity market. Initially we started our approach through to simple stochastic models for electricity pricing. And we derived analytical formulas for prices of electricity derivatives with different derivatives tools. 3) Then we extended short of the model for price risk in the electricity spot market. Finally, we constructed the model estimation under the physical measures for Colombian electricity market. And this paper end with conclusion.

\section{References}

Barlow, M. T. (2002). A diffusion model for electricity prices, Mathematical Finance 12, 287-298.

Black, F., (1976). The Pricing of Commodity Contracts, Journal of Financial Economics 3, $167-179$.

Box, G. E. P., and Jenkins, G. M. (1976). Time Series Analysis: Forecasting and Control, (Revised Edition) Holden-Day, San Francisco, 1976.

Chao, H., and Wilson, R. (nd). Resource adequacy and market power mitigation via option contracts, POWER Ninth Annual Research Conference.

Clewlow, L., and Strickland, C. (1999). Valuing Energy Options in a One Factor Model Fitted to Forward Prices, Working Paper, University of Sydney.

De Jong, C., and Huisman, R. (2002). Option formulas for mean-reverting power prices with spikes, Working Paper, Erasmus University Rotterdam, 2002.

Deng, S. (2000). Stochastic Models of Energy Commodity Prices and Their Applications: Mean-reversion with Jumps and Spikes, Working paper, Georgia Institute of Technology.

Deng, S., and Oren, S. (2006). Electricity derivatives and risk management, Energy Vol. 31. pp. 940 - 953.

Elliott, R. J., Sick, G. A. and Stein, M. (2003). Modeling Electricity Price Risk, Preprint, University of Calgary.

Elliott, R. J., Sick, G. A., and Stein, M. (2003). Modelling Electricity Price Risk, Preprint, University of Calgary.

Eydeland, and Geman, H. (1999). Fundamentals of Electricity Derivatives, in: Energy Modeling and the Management of Uncertainty, (pp. 35 \{43), Risk Books, London, 1999. 
Vol 2, No.3, September 2021

Geman, H., Roncoroni, A. (2003). A Class of Marked Point Processes for Modeling Electricity Prices, Preprint, ESSEC Business School, Cergy-Pontoise.

Gibson, R and Schwartz, E. S. (1990). Stochastic convenience yield and the pricing of oil contingent claims. Journal of Finance 45, 959 - 976.

Gibson, R., and Schwartz, E. S. (1990). Stochastic convenience yield and the pricing of oil contingent claims, Journal of Finance 45, 959 - 976.

Heath, D., Jarrow, R., and Morton, A. (1992). Bond pricing and the term structure of interest rates: a new methodology, Econometrica 60, 77 - 105.

Heath, D., Jarrow, R., Morton, A. (1992). Bond pricing and the term structure of interest rates: a new methodology, Econometrica 60, 77 - 105.

Huisman, and Mahieu, R. (2001). Regime Jumps in Electricity Prices, Working Paper, Erasmus University Rotterdam, 2001.

Huisman, R., Mahieu, R., and Schlichter, F. (nd). Electricity portfolio management: Optimal peak / off-peak allocations, Research in Management.

Hull J. (2000). Options, futures, and other derivative, 4th Edition, Prentice-Hall, Englewood, NJ.

Kholodnyi, V. A. (July 2000). The Stochastic Process for Power Prices with Spikes and Valuation of European Contingent Claims on Power, Preprint, TXU- RAG-01/00.

Knittel, S., and Roberts, M. (2001). An Empirical Examination of Deregulated Electricity Prices, Boston University, POWER Working Paper PWP-087.

Koekebakker, S and Ollmar, F. (2001). Forward curve dynamics in the Nordic electricity market, Preprint, Norwegian School of Econonimics and Business Administration.

Liu, M., and Wu, F. (2007). Risk management in a competitive electricity market, Electrical Power and Energy Systems Vol. 29. pp. 690 - 697.

Manoliu, M and Tompaidis, S. (2002). Energy Futures Prices: Term Strucuture Models with Kalman Filter Estimation. Applied Mathematical Finance 9. 21 - 43.

Oum, Y., Oren, S. (nd). Optimal static hedging of volumetric risk in a competitive wholesale electricity market, Management Science (in press).

Oum, Y., Oren, S., and Deng, S. (2006). Hedging quantity risks with standard power options in a competitive wholesale - Electricity market, Special Issue on Applications of Financial Engineering in Operations, Production, Services, Logistics, and Management, Naval Research Logistics Vol. 53 (2006) pp. 697 712.

Pilipovic, D. (1988). Energy Risk: Valuing and Managing Energy Derivatives, McGrawHill, New York.

Prokopczuk, M., Rachev, S., Schindlmayr, G., and Truck, S. (nd). Quantifying risk in the electricity business: A RAROC - based approach, Energy Economics Vol. 29. 
Vol 2, No.3, September 2021

Schwartz, E. and Smith, J. E. (2000). Short-Term Variations and long-term dynamics in commodity prices, Management Science 46, 893 - 911.

Skantze, P., Gubina, A., and Ilic, M. (2000). Bid-based stochastic model for electricity prices: The impact of fundamental drivers on market dynamics Report, MIT Energy Laboratory (2000).

Tseng, C. L. T., and Barz, G. (2002). Short-term Generation Asset Valuation: a Real Options Approach, Operations Research 50 (2002), 297 - 310.

Villareal, J., and Soto, C (nd). Ensuring generation adequacy with firm energy call options: A case study for the hydro - dependent Colombian system.

\section{Copyrights}

Copyright for this article is retained by the author(s), with first publication rights granted to the journal.

This is an open-access article distributed under the terms and conditions of the Creative Commons Attribution license (http://creativecommons.org/licenses/by/4.0/) 